\title{
Anti-tumor peptide SA12 inhibits metastasis of MDA-MB-231 and MCF-7 breast cancer cells via increasing expression of the tumor metastasis suppressor genes, CDH1, nm23-H1 and BRMS1
}

\author{
LONGFEI YANG, FANG LIN, ZHAOWEI GAO, XI CHEN, HUIZHONG ZHANG and KE DONG \\ Department of Medical Laboratory and Research Center, Tangdu Hospital, \\ Fourth Military Medical University, Xi'an, Shaanxi 710038, P.R. China
}

Received September 16, 2019; Accepted April 29, 2020

DOI: $10.3892 / \mathrm{etm} .2020 .8886$

\begin{abstract}
In recent years, there has been progress in the treatment of breast cancer; however, the prognosis is still poor due to recurrence and metastasis following conventional treatment. The anti-tumor peptide SA12 has been demonstrated to inhibit proliferation and arrest the cell cycle in MDA-MB-231 and MCF-7 breast cancer cells. In the present study, whether SA12 was able to inhibit the metastasis of breast cancer cells was investigated. Wound healing and Transwell assays were used to investigate the inhibition of SA12 on cell migration while, reverse transcription-quantitative PCR and western blot assays were used to identify the mechanism of action behind the effects of SA12 on cell migration. Results from the wound healing and Transwell assays revealed that SA12 significantly inhibited the migration of MDA-MB-231 and MCF-7 breast cancer cells following treatment with $100 \mu \mathrm{M} \mathrm{SA} 12$. Compared with that in the controls, the mRNA expression levels of cadherin 1 (CDH1), non-metastasis 23-H1 (nm23-H1) and breast cancer metastasis suppressor 1 (BRMS1) were increased in MDA-MB-231 and MCF-7 cells following treatment with $100 \mu \mathrm{M}$ SA12. Furthermore, the protein expression levels of E-cadherin, NM23A and BRMS1 were also increased in MDA-MB-231 cells and MCF-7 cells following treatment with $100 \mu \mathrm{M}$ SA12. In conclusion, SA12 inhibited the migration of MDA-MB-231 and MCF-7 breast cancer cells and enhanced the expression of the tumor metastasis suppressor genes, CDH1, nm23-H1 and BRMS1, which may be responsible for the SA12-induced inhibition of breast cancer cell metastasis.
\end{abstract}

Correspondence to: Dr Ke Dong or Dr Huizhong Zhang, Department of Medical Laboratory and Research Center, Tangdu Hospital, Fourth Military Medical University, 569 Xinsi Road, Xi'an, Shaanxi 710038, P.R. China

E-mail: drdongke@163.com

E-mail: huizz328@163.com

Key words: breast cancer, anti-tumor peptide SA12, tumor metastasis suppressor gene, cadherin 1 , non-metastasis $23-\mathrm{H} 1$, breast cancer metastasis suppressor 1

\section{Introduction}

Breast cancer is one of the most common malignant tumor types and is also one of the leading causes of cancer-associated mortality worldwide (1). Over the past few decades, surgical treatment, radiotherapy, chemotherapy and endocrine therapy have been utilized for the clinical treatment of breast cancer. However, the prognosis for patients with breast cancer remains poor due to the recurrence and metastasis of breast cancer following conventional treatment (2).

Bioactive peptides, which are composed of several amino acids, have been indicated to be effective as a novel therapeutic strategy in cancer therapies (3). Previous studies have revealed that a novel anti-tumor peptide, SA12, inhibits proliferation and arrests the cell cycle in MDA-MB-231 and MCF-7 breast cancer cells $(4,5)$. Tumor metastasis is critical in the progression of breast cancer, which is regulated by a number of genes. Tumor metastasis suppressor genes, including cadherin 1 (CDH1), non-metastasis 23-H1 (nm23-H1) and breast cancer metastasis suppressor 1 (BRMS1) are important negative regulators during tumor metastasis (6,7). E-cadherin, which is the gene encoding the product of CDH1, is downregulated in a number of cancer types during the epithelial-mesenchymal transition and its expression is inversely correlated with metastasis. Overexpression of E-cadherin suppresses the invasion of cancer cells (6). Non-metastatic 23A (NM23A), a potential metastasis suppressor encoded by the nm23-H1 gene, was identified as a metastasis suppressor in melanoma cells. NM23A expression has been identified to be inversely correlated with clinical metastasis of multiple tumors, mediating suppression of metastasis and controlling cellular responses to the microenvironment (7). BRMS1 is currently the only metastasis suppressor that has been identified in models of breast cancer and has since been revealed to suppress metastasis in a broad spectrum of cancer types, regulating the interactions between tumor cells and the tumor microenvironment (6). The present study aimed to explore whether the anti-cancer peptide SA12 inhibited the metastasis of MDA-MB-231 and MCF-7 breast cancer cells and to further investigate the roles of the tumor metastasis suppressor genes, $\mathrm{CDH} 1, \mathrm{~nm} 23-\mathrm{H} 1$ and BRMS1, as well as their gene encoding products, E-cadherin, NM23A and BRMS1, in the inhibition of SA12 in MDA-MB-231 and MCF-7 cells. 


\section{Materials and methods}

Reagents.DMEMandFBS were purchased from Gibco; Thermo Fisher Scientific, Inc. Bovine serum albumin and trypsin were purchased from Invitrogen; Thermo Fisher Scientific, Inc. Cell culture plates and Transwell chambers were purchased from Corning Inc. RNAiso Plus reagent, PrimeScript RT reagent kit and SYBR Premix Ex Taq II were purchased from Takara Biotechnology Co., Ltd. RIPA lysis buffer was purchased from Sangon Biotech Co., Ltd. The mouse anti-human E-cadherin monoclonal antibody (cat. no. ab1416), the rabbit anti-human NM23A polyclonal antibody (cat. no. ab92327) and the rabbit anti-human BRMS1 monoclonal antibody (cat. no. ab134968) were purchased from Abcam. The mouse anti-human $\beta$-actin monoclonal antibody (cat. no. TA328071), the horseradish (HRP)-labelled goat anti-mouse secondary antibody (cat. no. TA130003) and the HRP-labelled goat anti-rabbit secondary antibody (cat. no. TA140003) were purchased from OriGene Technologies, Inc.

Cell lines and culture. Human MDA-MB-231 and MCF-7 cell lines were purchased from the American Type Culture Collection and cultured in DMEM medium containing $10 \% \mathrm{FBS}$ at $37^{\circ} \mathrm{C}$ in an atmosphere of $5 \% \mathrm{CO}_{2}$.

Peptide preparation. The amino acid sequence of SA12 used in the present study was Ser-Val-Pro-Leu-Phe-Asn-Phe-Ser-V al-Tyr-Leu-Ala. The peptide was chemically synthesized and purified by GL Biochem Shanghai, Ltd. The synthetic peptide was dissolved in DMSO using ultrasound and vortexed for $30 \mathrm{sec}$ at $200 \mathrm{x} \mathrm{g}$, and then diluted to $100 \mu \mathrm{M}$ in DMEM.

Wound healing assay. MDA-MB-231 and MCF-7 cells were seeded into 6-well cell culture plates with a density of $5 \times 10^{5}$ cells/well at $37^{\circ} \mathrm{C}$ overnight. Upon reaching $80 \%$ confluence, the cells were scratched using a micropipette tip and the floating cells were removed through PBS solution washes. The cells were treated with $100 \mu \mathrm{M}$ SA12 diluted in serum-free DMEM, while the serum-free DMEM containing 0.1\% DMSO was used as the blank control. Cells were incubated at $37^{\circ} \mathrm{C}$ for $48 \mathrm{~h}$ without changing the medium, and wound healing was examined using a phase contrast microscope (Olympus Corporation) at $\mathrm{x} 200$ magnification. The cell migration distance was measured and the migration distance at $48 \mathrm{~h}$ was normalized to the distance at $0 \mathrm{~h}$ in each sample.

Transwell assay. A total of $500 \mu 1$ serum-free DMEM containing $50 \mu \mathrm{l}$ bovine serum albumin $(10 \mathrm{~g} / \mathrm{l})$ was added to each Transwell chamber and incubated at $37^{\circ} \mathrm{C}$ for $30 \mathrm{~min}$ to hydrate the basement membrane. MDA-MB-231 and MCF-7 cells were cultured until $90 \%$ confluent at $37^{\circ} \mathrm{C}$, and the serum was removed to starve the cells for $12 \mathrm{~h}$. The cells were then digested with trypsin and centrifuged at $200 \mathrm{x}$ g for $5 \mathrm{~min}$ at room temperature. The cell pellets were resuspended in serum-free medium at a cell density of $5 \times 10^{5}$ cells $/ \mathrm{ml}$. The Transwell chambers were placed in the 24-well cell culture plates with $500 \mu 1$ DMEM per well and $200 \mu 1$ prepared cell suspension was added into the Transwell chamber. The cells were treated with $100 \mu \mathrm{M}$ SA12 diluted in DMEM and the control group was treated with serum-free cell culture medium
Table I. Primers designed for reverse transcription-quantitative PCR.

\begin{tabular}{ll} 
Gene & \multicolumn{1}{c}{ Primer } \\
\hline CDH1 & F: 5'-GAACGCATTGCCACATACAC-3' \\
& R: 5'-GAATTCGGGCTTGTTGTCAT-3' \\
nm23-H1 & F: 5'-AGAAAGGATTCCGCCTTGTT-3' \\
& R: 5'-GGCCCTGAGTGCATGTATTT-3' \\
BRMS1 & F: 5'-GCAGCGGAGCCTCAAGATTCG-3' \\
& R: 5'-GCAGCGTGTCATAGAGCAGCAG-3' \\
$\beta$-actin & F: 5'-GACTTAGTTGCGTTACACCCTTTC-3' \\
& R: 5'-TGCTGTCACCTTCACCGTTC-3' \\
\hline
\end{tabular}

F, forward; R, reverse; BRMS1, breast cancer metastasis suppressor 1; CDH1, cadherin 1; nm23-H1, non-metastasis 23-H1.

containing 0.1\% DMSO. In order to prevent cell proliferation caused by the serum in the lower chambers, the cells were collected following incubation for $24 \mathrm{~h}$ at $37^{\circ} \mathrm{C}$, without medium changes. The cells were fixed with $2 \%$ glutaraldehyde for $30 \mathrm{~min}$ and stained with $0.2 \%$ gentian violet (Baso Diagnostic, Inc.) for $10 \mathrm{~min}$ at temperature. The migrated cells were photographed using a phase contrast microscope (Olympus Corporation) at x200 magnification. The number of migrated cells in 5 visual fields was randomly counted using ImageJ 1.8.0 software (National Institutes of Health) and the average number was calculated to determine the cell mobility in cells following SA12 treatment.

Reverse transcription-quantitative PCR (RT-qPCR) analysis. The MDA-MB-231 and MCF-7 breast cancer cell lines were seeded into 6 -well plates at a density of $5 \times 10^{5}$ cells/well and cultured at $37^{\circ} \mathrm{C}$. Cells were treated with $100 \mu \mathrm{M} \mathrm{SA} 12$ diluted in DMEM for $48 \mathrm{~h}$ at $37^{\circ} \mathrm{C}$, and cells were treated with DMEM containing $0.1 \%$ DMSO as a control for $48 \mathrm{~h}$ at $37^{\circ} \mathrm{C}$. RNAiso plus reagent (Takara Bio, Inc.) was used to extract total RNA and subsequently, the obtained RNA was dried naturally at room temperature and dissolved in $50 \mu \mathrm{l}$ RNase-free water. PrimeScript RT reagent kit (Takara Bio, Inc.) was used to reverse transcribe $\mathrm{mRNA}$ to generate $\mathrm{cDNA}$ at $37^{\circ} \mathrm{C}$ for $15 \mathrm{~min}$ and $85^{\circ} \mathrm{C}$ for $5 \mathrm{sec}$. CDH1, nm23-H1 and BRMS1 cDNA were amplified using SYBR Premix Ex Taq II (Takara Bio, Inc.), with primers provided in Table I. $\beta$-actin was used as the internal control. The following thermocycling conditions were used for the qPCR: Initial denaturation at $95^{\circ} \mathrm{C}$ for $3 \mathrm{~min}$; 40 cycles of $95^{\circ} \mathrm{C}$ for $15 \mathrm{sec}, 54^{\circ} \mathrm{C}$ for $20 \mathrm{sec}$ and $72^{\circ} \mathrm{C}$ for $20 \mathrm{sec}$; and a final extension at $72^{\circ} \mathrm{C}$ for $10 \mathrm{~min}$. The relative mRNA expression levels were calculated as fold changes using the $2^{-\Delta \Delta \mathrm{Cq}}$ method (8) to reflect the changes of CDH1, nm23-H1 and BRMS1 genes following treatment with SA12.

Western blot analysis. The MDA-MB-231 and MCF-7 breast cancer cell lines were seeded into 6-well plates at a density of $5 \times 10^{5}$ cells/well and treated with $100 \mu \mathrm{M}$ SA12 diluted in DMEM for $48 \mathrm{~h}$ at $37^{\circ} \mathrm{C}$. Cells treated with DMEM containing $0.1 \%$ DMSO were used as the control. The cells 
were harvested following digestion with trypsin, centrifuged at $200 \mathrm{x}$ g for $5 \mathrm{~min}$ at room temperature, lysed with $200 \mu \mathrm{l}$ RIPA lysis buffer (Beyotime Institute of Biotechnology) containing $2 \mu \mathrm{l}$ PMSF (100 mM) (Beyotime Institute of Biotechnology), and incubated for $30 \mathrm{~min}$ on ice. The lysate was centrifuged at $14,000 \mathrm{x}$ g for $15 \mathrm{~min}$ at $4^{\circ} \mathrm{C}$, the supernatant was extracted, and the concentration of total protein was calculated using a bicinchoninic acid assay (Beyotime Institute of Biotechnology). Subsequently, $80 \mu \mathrm{g}$ protein/lane was separated via 12\% SDS-PAGE (Beyotime Institute of Biotechnology). Subsequently, the proteins were transferred onto nitrocellulose membranes and blocked with 5\% skimmed milk for $30 \mathrm{~min}$ at room temperature. The membranes were then incubated with E-cadherin (1:50), NM23A $(1: 1,000)$ and BRMS1 $(1: 1,000)$ primary antibodies overnight at $4^{\circ} \mathrm{C}$, and subsequently with the goat anti-mouse or goat anti-rabbit HRP-labeled secondary antibodies $(1: 2,000)$ for $2 \mathrm{~h}$ at room temperature. The protein signals were visualized using ECL (EMD Millipore). The density of bands in SA12 treated cells and controls were compared and normalized to $\beta$-actin $(1: 1,000)$, which was used as the internal control. The relative protein expression levels of E-cadherin, NM23A and BRMS1 after SA12 treatment were calculated using Gel-Pro Analyzer 4.0 software (Media Cybernetics, Inc.).

Statistical analysis. All the experiments were repeated at least 3 times and the results are presented as the mean \pm standard deviation. Data were analyzed using unpaired or paired Student's t-tests. $\mathrm{P}<0.05$ was considered to indicate a statistically significant difference. SPSS v14.0 software (SPSS, Inc.) was used for statistical analysis.

\section{Results}

SA12 inhibits the migration of MDA-MB-231 and MCF-7 cells in wound healing assays. To examine the inhibitory effect of SA12 on the migration of MDA-MB-231 and MCF-7 breast cancer cells, wound healing assays were performed. The cells were treated with $100 \mu \mathrm{M}$ SA12, while the control group was treated with $0.1 \%$ DMSO. The cells in each group were cultured for $48 \mathrm{~h}$ and images were obtained. The results revealed that SA12 inhibited the migration of MDA-MB-231 and MCF-7 breast cancer cells, and the cell migration distances were reduced compared with the control group ( $\mathrm{P}<0.05$; Fig. 1). The percentage of migrated cells was 51.3 and $34.6 \%$ in MDA-MB-231 and MCF-7 cells, compared with the control group, respectively (data not shown).

SA12 inhibits the migration of MDA-MB-231 and MCF-7 cells in Transwell assays. To further determine the inhibitory effect of SA12 on the migration of MDA-MB-231 and MCF-7 breast cancer cells, Transwell assays were performed. The cells were treated with $100 \mu \mathrm{M} \mathrm{SA} 12$, with $0.1 \%$ DMSO-treated cells used as the control. The cells were harvested following $24 \mathrm{~h}$ incubation and the number of cells migrated from the basement membrane of the upper chambers in 5 visual fields was counted and the average number was calculated. The results revealed that SA12 significantly inhibited the migration of MDA-MB-231 and MCF-7 breast cancer cells following $24 \mathrm{~h}$ of treatment, and the number of migrated cells were

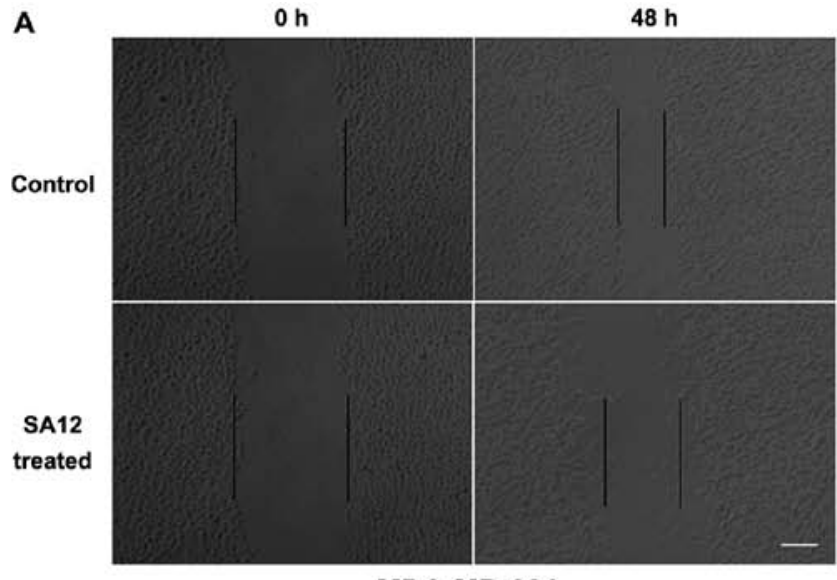

MDA-MB-231
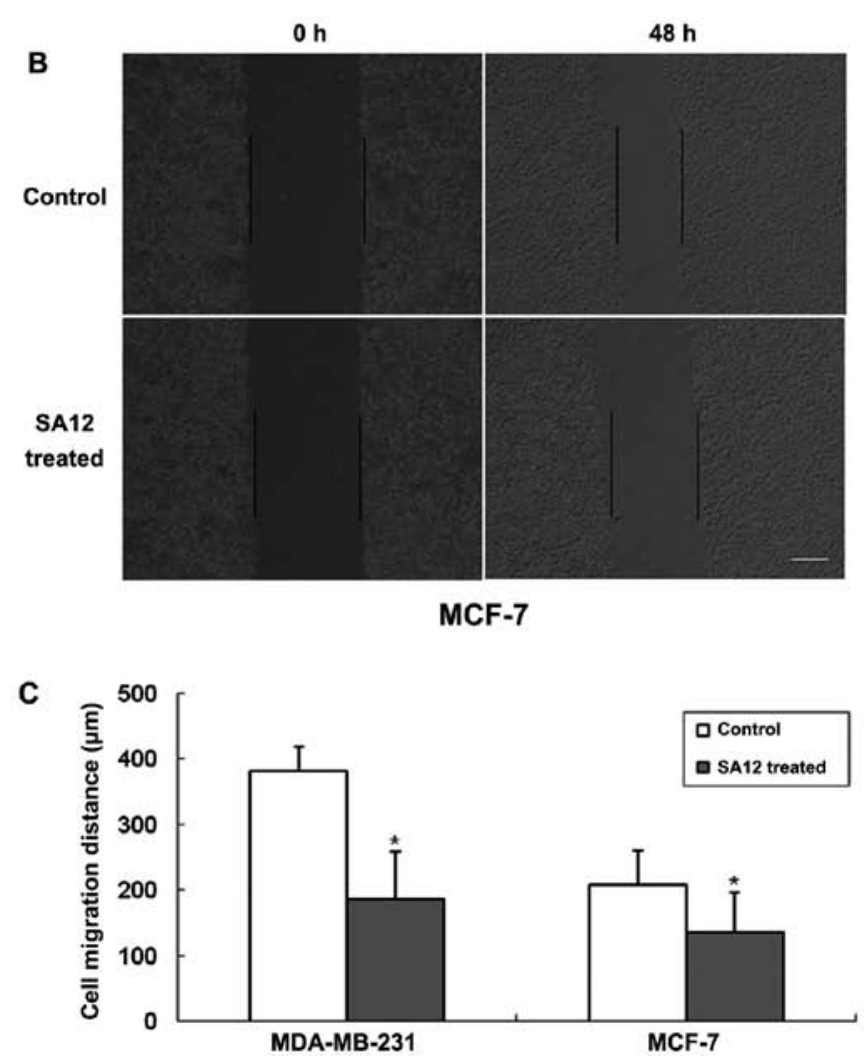

Figure 1. SA12 inhibited the migration of breast cancer cells in wound healing assays. SA12 inhibited the migration of (A) MDA-MB-231 and (B) MCF-7 breast cancer cells following $48 \mathrm{~h}$ of treatment. (C) Quantification of the extent of wound closure. Scale bars represent $200 \mu \mathrm{m}$. " $\mathrm{P}<0.05$ vs. the corresponding control group.

decreased compared with the control groups ( $\mathrm{P}<0.05$; Fig. 2). The percentage of migrated cells was 38.2 and $29.8 \%$ in MDA-MB-231 and MCF-7 cells, respectively, compared with the controls (data not shown). These results revealed that SA12 inhibited the migration of breast cancer MDA-MB-231 and MCF-7 cells.

SA12 increases the mRNA expression levels of CDH1, nm23-H1 and BRMS1. The tumor metastasis suppressor genes, CDH1, nm23-H1 and BRMS1 are important negative regulators in tumor metastasis (6). To investigate the possible mechanism of action behind how SA12 inhibited the metastasis of MDA-MB-231 and MCF-7 breast cancer cells, the 

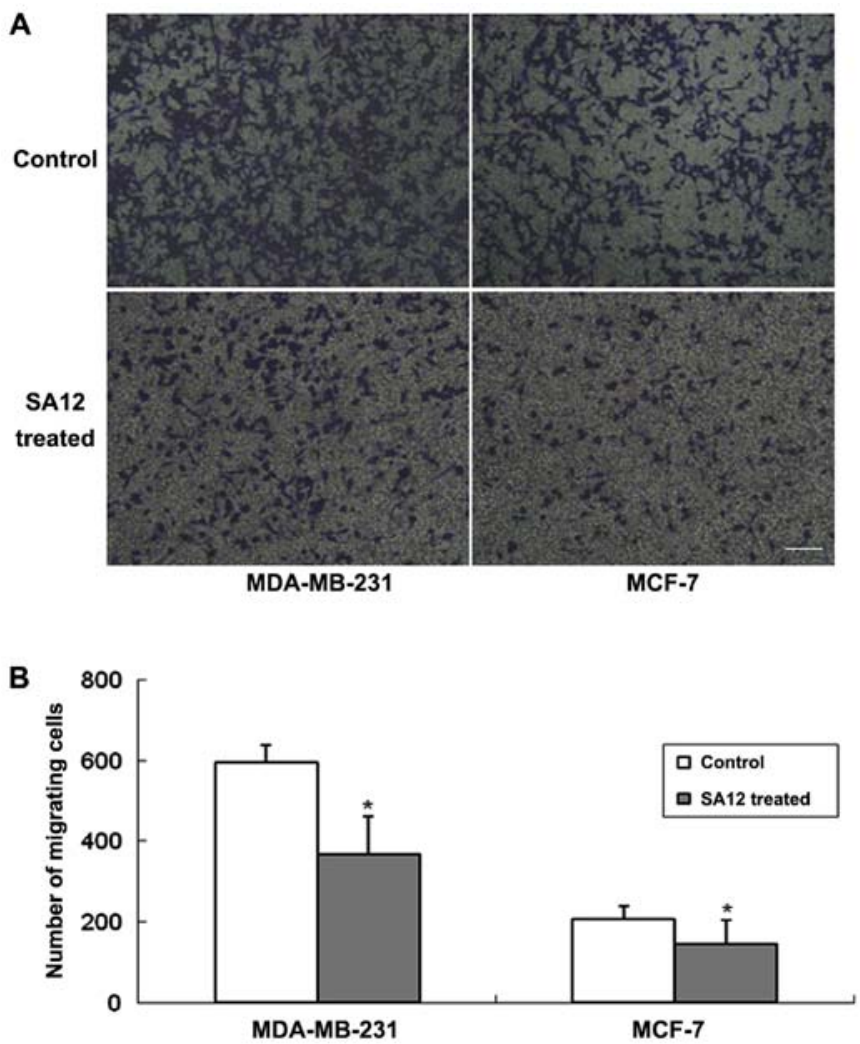

Figure 2. SA12 inhibited the migration of breast cancer cells in Transwell assays. (A) SA12 inhibited the migration of MDA-MB-231 and MCF-7 breast cancer cells after $24 \mathrm{~h}$ of treatment. (B) The number of migrating cells was found to significantly decrease in both cell lines after treatment. Scale bar represents $200 \mu \mathrm{m}$. ${ }^{*} \mathrm{P}<0.05$ vs. the corresponding control group.

mRNA expression levels of CDH1, nm23-H1 and BRMS1 were detected using RT-qPCR. As presented in Fig. 3, the mRNA expression levels of CDH1, $\mathrm{nm} 23-\mathrm{H} 1$ and BRMS1 were significantly increased after treatment with $100 \mu \mathrm{M}$ SA12 for $48 \mathrm{~h}$ (all $\mathrm{P}<0.05$ ). The percentage increase in the mRNA levels of the aforementioned markers in MDA-MB cells compared with that in the controls was 51.9, 30.2 and 22.3\%, respectively, and 26.1,34.4 and $17.2 \%$, respectively, in MCF-7 cells. These results suggested that treatment with SA12 significantly increased the mRNA expression levels of CDH1, $\mathrm{nm} 23-\mathrm{H} 1$ and BRMS1 in MDA-MB-231 and MCF-7 breast cancer cells.

SA12 enhances the protein expression levels of E-cadherin, $N M 23 A$ and BRMS1. To further verify the aforementioned results, the effect of SA12 on the protein expression levels of tumor metastasis suppressors E-cadherin, NM23A and BRMS1 in MDA-MB-231 and MCF-7 breast cancer cells were examined using western blot analysis. As presented in Fig. 4, following treatment with $100 \mu \mathrm{M} \mathrm{SA} 12$ for $48 \mathrm{~h}$, the protein expression levels of E-cadherin, NM23A and BRMS1 in MDA-MB-231 and MCF-7 cells was significantly increased (all $\mathrm{P}<0.05$ ). The percentage increase in the aforementioned protein levels in MDA-MB-231 cells compared with that in the controls was $42.1,76.3$ and $41.9 \%$, respectively, and 25.2, 32.8 and $23.0 \%$, respectively, in MCF-7 cells. The results indicated that the protein expression levels of E-cadherin, NM23A and BRMS1 were also increased following SA12

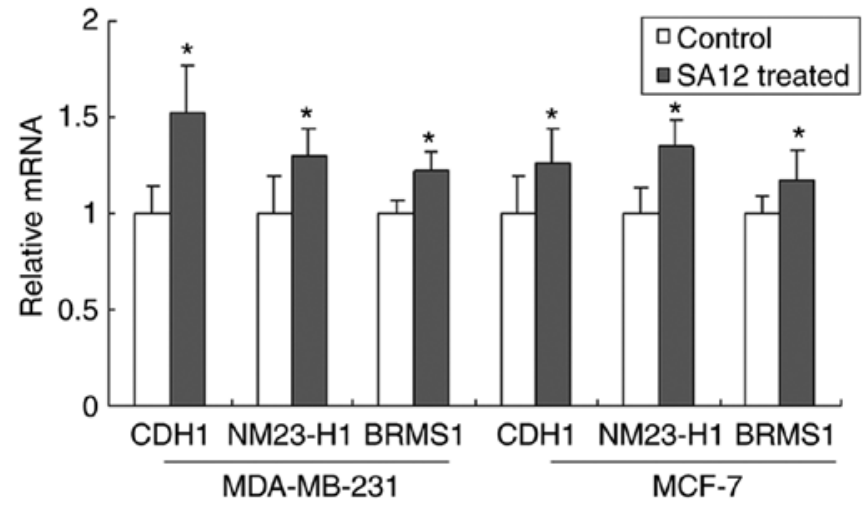

Figure 3. SA12 enhanced mRNA expression levels of CDH1, nm23-H1 and BRMS1. Compared with that in the controls, the mRNA expression levels of $\mathrm{CDH} 1, \mathrm{~nm} 23-\mathrm{H} 1$ and BRMS1 were increased in MDA-MB-231and MCF-7 cells after treatment with $100 \mu \mathrm{M} \mathrm{SA} 12 .{ }^{*} \mathrm{P}<0.05$ vs. the corresponding control group. BRMS1, breast cancer metastasis suppressor 1; CDH1, cadherin 1; nm23-H1, non-metastasis $23-\mathrm{H} 1$.

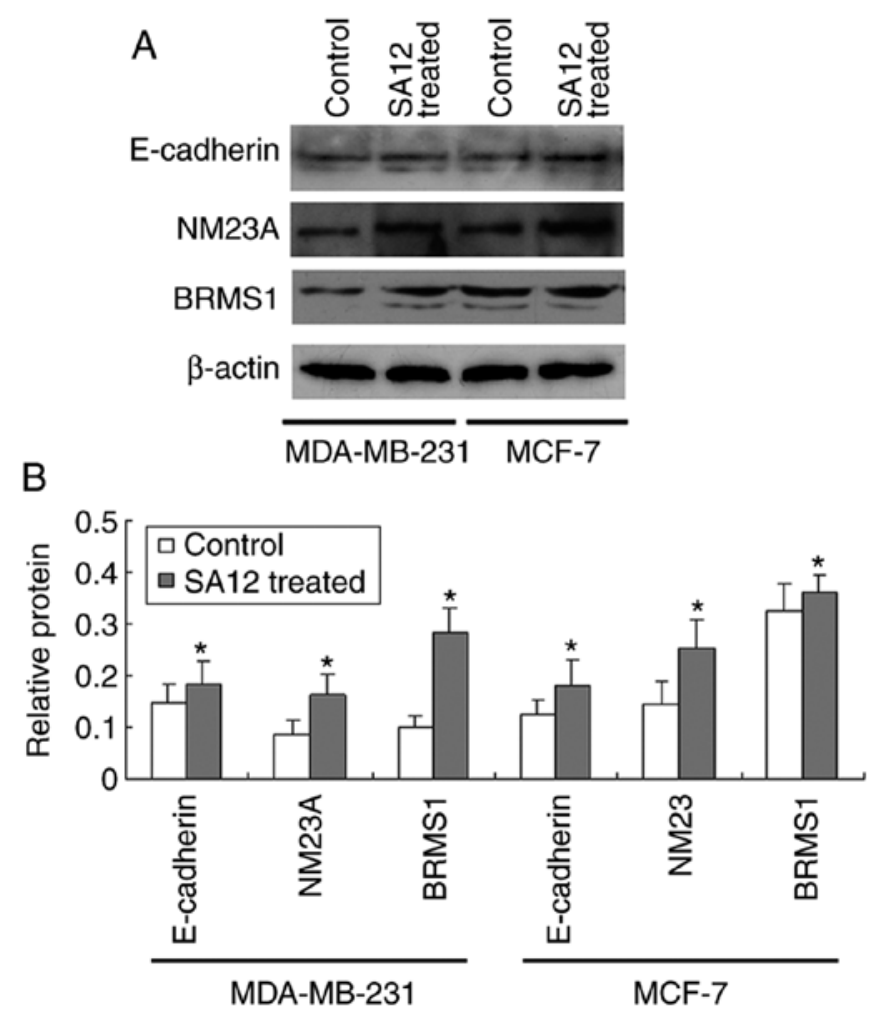

Figure 4. SA12 enhanced protein expression levels of E-cadherin, NM23A and BRMS1. (A) After treatment with $100 \mu \mathrm{M} \mathrm{SA} 12$ for $48 \mathrm{~h}$, the protein expression levels of E-cadherin, NM23A and BRMS1 in MDA-MB-231 and MCF-7 cells were increased. (B) The percentage of E-cadherin, NM23A and BRMS1 protein expression levels were increased in MDA-MB-231 and MCF-7 cells compared with that in the controls. ${ }^{*} \mathrm{P}<0.05$ vs. the corresponding control group. BRMS1, breast cancer metastasis suppressor 1; NM23A, non-metastatic 23A..

treatment. SA12 increased the expression of the tumor metastasis suppressors E-cadherin, NM23A and BRMS1 in MDA-MB-231 and MCF-7 cells. The upregulation of E-cadherin, NM23A and BRMS1 may be responsible for the SA12-induced inhibition of metastasis to the MDA-MB-231 and MCF-7 cells. 


\section{Discussion}

Malignant tumor metastasis is a complex biological process, involving a number of cellular interactions between tumor and stroma cells. Metastasis occurs when tumor cells break away from the primary tumor and migrate through the extracellular matrix (9). Tumor metastasis suppressor genes, including CDH1, nm23-H1 and BRMS1 are important negative regulators, which serve important roles in inhibiting tumor metastasis $(6,7,10)$. A previous study identified an anti-tumor peptide SA12, which was indicated to inhibit proliferation and arrest the cell cycle of MDA-MB-231 and MCF-7 breast cancer cells $(4,5)$. In the present study, the anti-tumor peptide SA12 inhibited the migration of MDA-MB-231 and MCF-7 breast cancer cells and enhanced the expression of the tumor metastasis suppressor genes, CDH1, nm23-H1 and BRMS1. These genes were also demonstrated to be associated with the SA12-induced inhibition of breast cancer cell migration.

Breast cancer metastasis is one of the leading causes of mortality in women and is regulated by adhesion molecules such as the cadherin superfamily (11). E-cadherin, which is the gene encoding product of $\mathrm{CDH} 1$, is an important member of the cadherin superfamily, which maintains the balance of cell-cell and cell-extracellular matrix adhesion (12). E-cadherin is a transmembrane glycoprotein expressed in human epithelial tissues, which connects epithelial cells together and serve a role in cell adhesion, cell morphology and cell movement (13). Intercellular adhesion serves an important role in the invasion and metastasis of tumor cells (14). Dysregulation of E-cadherin in tumors is associated with the epithelial-mesenchymal transition and subsequently induces tumor cell dissemination as well as promoting cell migration and invasion (15). E-cadherin supports the function of cell adhesion molecules in the repression of tumor metastasis in breast cancer $(11,16)$. Studies from a meta-analysis revealed that reduced E-cadherin expression levels are associated with a poorer prognosis in breast cancer tissue; therefore, may be a potential therapeutic target for treating breast cancer (17). In the present study, the anti-tumor peptide SA12 was indicated to enhance the expression of the tumor metastasis suppressor gene CDH1 in MDA-MB-231 and MCF-7 cells. These results are consistent with a previous report that revealed that E-cadherin influences the imbalance of homogeneous adhesion between tumor cells and heterogeneous adhesion between tumor cells and stromal cells (18). This imbalance is crucial for the detachment of tumor cells from the primary tumor and for the invasion or metastasis of independent tumor cells (19-21).

Furthermore, the present study revealed that SA12 treatment increased the expression of $\mathrm{nm} 23-\mathrm{H} 1$ and BRMS1 in MDA-MB-231 and MCF-7 cells, which are also tumor metastasis suppressor genes. NM23A, which is a potential metastasis suppressor encoded by the $\mathrm{nm} 23-\mathrm{H} 1$ gene $(22,23)$, was indicated to be highly expressed in differentiated tissues, but at lower levels in breast cancer, gastric cancer, bladder cancer, intestinal cancer and osteosarcoma tissues $(24,25)$. The expression levels of $\mathrm{nm} 23-\mathrm{H} 1$ are negatively correlated with lymph node metastasis and reflect the metastatic ability of tumors (26-28). Phosphorylation of kinase suppressor of Ras1 (KSR1)-serine392 by NM23A is known to reduce ERK activation and inhibit the ERK-MAPK signaling pathway, which serves a crucial role in cancer metastasis (29). Another important tumor metastasis suppressor gene, BRMS1, which was discovered in breast carcinoma cells, has since been identified to suppress metastasis in a variety of cancer types (30). A previous study demonstrated that BRMS1 regulates the interactions between tumor cells and the tumor microenvironment, affecting the key events of metastasis, including the inhibition of migration and invasion, as well as the initiation of growth by single cells and promotion of anoikis (31). Increased expression of BRMS1 restores the homotypic and heterotypic intercellular communication of gap junctions (30). Additionally, a role for BRMS1 in transcriptional regulation has also been revealed since the identification of BRMS1 in the mammalian Sin3 histone deacetylase complex $(30,31)$.

In conclusion, the anti-tumor peptide SA12 was revealed to inhibit the metastasis of MDA-MB-231 and MCF-7 breast cancer cells in the current study. SA12 enhanced the expression of the tumor metastasis suppressor genes, $\mathrm{CDH} 1, \mathrm{~nm} 23-\mathrm{H} 1$ and BRMS1, and maybe responsible for SA12-induced inhibition of metastasis in MDA-MB-231 and MCF-7 cells. To more conclusively demonstrate that $\mathrm{CDH} 1, \mathrm{~nm}-23-\mathrm{H} 1$ and BRMS1 are involved in this suppression, knockdown experiments should be performed, which is a limitation of the present study and a future direction for research. A more in-depth study should focus on the detailed molecular mechanisms of action behind the reduction in angiogenesis induced by SA12. Further studies to reveal the molecular mechanisms of action underlying the SA12-induced inhibition of breast cancer cell metastasis and the involvement of tumor metastasis suppressor genes in the cell signal pathways are required to expand on the findings of the present study.

\section{Acknowledgements}

Not applicable.

\section{Funding}

This study was supported by the Natural Science Foundation of China (grant no. 81502671).

\section{Availability of data and materials}

The datasets used and/or analyzed during the current study are available from the corresponding author on reasonable request.

\section{Authors' contributions}

LY designed the study, acquired the data and drafted the manuscript; FL performed the statistical analysis; ZG processed the data; XC analyzed the results; KD and HZ interpreted the data and revised the manuscript critically for important intellectual content. All authors read and approved the final manuscript.

\section{Ethics approval and consent to participate}

Not applicable.

\section{Patient consent for publication}

Not applicable. 


\section{Competing interests}

The authors declare that they have no competing interests.

\section{References}

1. Jamdade VS, Sethi N, Mundhe NA, Kumar P, Lahkar M and Sinha N: Therapeutic targets of triple-negative breast cancer: A review. Br J Pharmacol 172: 4228-4237, 2015.

2. Nagini S: Breast cancer: Current molecular therapeutic targets and new players. Anticancer Agents Med Chem 17: 152-163, 2017.

3. Li ZJ and Cho CH: Development of peptides as potential drugs for cancer therapy. Curr Pharm Des 16: 1180-1189, 2010.

4. Yang L, Cui Y, Shen J, Lin F, Wang X, Long M, Wei J and Zhang H: Antitumor activity of SA12, a novel peptide, on SKBr-3 breast cancer cells via the mitochondrial apoptosis pathway. Drug Des Devel Ther 9: 1319-1330, 2015.

5. Yang L, Liu H, Long M, Wang X, Lin F, Gao Z and Zhang H: Peptide SA12 inhibits proliferation of breast cancer cell lines MCF-7 and MDA-MB-231 through G0/G1 phase cell cycle arrest. OncoTargets Ther 11: 2409-2417, 2018.

6. Bodenstine TM and Welch DR: Metastasis suppressors and the tumor microenvironment. Cancer Microenviron 1: 1-11, 2008.

7. Bohl CR, Harihar S, Denning WL, Sharma R and Welch DR: Metastasis suppressors in breast cancers: Mechanistic insights and clinical potential. J Mol Med (Berl) 92: 13-30, 2014.

8. Livak KJ and Schmittgen TD: Analysis of relative gene expression data using real-time quantitative PCR and the 2(-Delta Delta C(T)) method. Methods 25: 402-408, 2001

9. Robert J: Biology of cancer metastasis. Bull Cancer 100: 333-342, 2013 (In French).

10. Khan I and Steeg PS: Metastasis suppressors: Functional pathways. Lab Invest 98: 198-210, 2018.

11. Shen T, Zhang K, Siegal GP and Wei S: Prognostic value of E-cadherin and $\beta$-catenin in triple-negative breast cancer. Am J Clin Pathol 146: 603-610, 2016.

12. Hajra KM and Fearon ER: Cadherin and catenin alterations in human cancer. Genes Chromosomes Cancer 34: 255-268, 2002.

13. van Roy F and Berx G: The cell-cell adhesion molecule E-cadherin. Cell Mol Life Sci 65: 3756-3788, 2008.

14. Behrens $\mathbf{J}$ and Birchmeier W: Cell-cell adhesion in invasion and metastasis of carcinomas. Cancer Treat Res 71: 251-266, 1994

15. Wong SHM, Fang CM, Chuah LH, Leong CO and Ngai SC: E-cadherin: Its dysregulation in carcinogenesis and clinical implications. Crit Rev Oncol Hematol 121: 11-22, 2018.

16. Ashaie MA and Chowdhury EH: Cadherins: The superfamily critically involved in breast cancer. Curr Pharm Des 22: 616-638, 2016.

17. Li Z, Yin S, Zhang L, Liu W and Chen B: Prognostic value of reduced E-cadherin expression in breast cancer: A meta-analysis. Oncotarget 8: 16445-16455, 2017.

18. Shiozaki H, Tahara H, Oka H, Miyata M, Kobayashi K, Tamura S, Iihara K, Doki Y, Hirano S, Takeichi M, et al: Expression of immunoreactive E-cadherin adhesion molecules in human cancers. Am J Pathol 139: 17-23, 1991.
19. Oka H, Shiozaki H,Kobayashi K, Inoue M, Tahara H,Kobayashi T, Takatsuka Y, Matsuyoshi N, Hirano S, Takeichi M, et al: Expression of E-cadherin cell adhesion molecules in human breast cancer tissues and its relationship to metastasis. Cancer Res 53: 1696-1701, 1993.

20. Sawada K, Mitra AK, Radjabi AR, Bhaskar V, Kistner EO, Tretiakova M, Jagadeeswaran S, Montag A, Becker A, Kenny HA, et al: Loss of E-cadherin promotes ovarian cancer metastasis via $\alpha 5$-integrin, which is a therapeutic target. Cancer Res 68: 2329-2339, 2008.

21. Bremnes RM, Veve R, Hirsch FR and Franklin WA: The E-cadherin cell-cell adhesion complex and lung cancer invasion, metastasis, and prognosis. Lung Cancer 36: 115-124, 2002.

22. Novak M, Jarrett SG, McCorkle JR, Mellon I and Kaetzel DM: Multiple mechanisms underlie metastasis suppressor function of NM23-H1 in melanoma. Naunyn Schmiedebergs Arch Pharmacol 384: 433-438, 2011.

23. Steeg PS, Bevilacqua G, Pozzatti R, Liotta LA and Sobel ME: Altered expression of NM23, a gene associated with low tumor metastatic potential, during adenovirus 2 Ela inhibition of experimental metastasis. Cancer Res 48: 6550-6554, 1988.

24. Han W, Zhang C, Cao FY, Cao F, Jiang L and Ding HZ: Prognostic and clinicopathological value of NM23 expression in patients with breast cancer: A systematic review and meta-analysis. Curr Probl Cancer 41: 80-93, 2017.

25. Fang M, Tao Y, Liu Z, Huang H, Lao M, Huang L and Zhu B: Meta-analysis of the relationship between NM23 expression to gastric cancer risk and clinical features. BioMed Res Int 2017: 8047183, 2017.

26. Ouatas T, Salerno M, Palmieri D and Steeg PS: Basic and translational advances in cancer metastasis: Nm23. J Bioenerg Biomembr 35: 73-79, 2003.

27. Steeg PS, de la Rosa A, Flatow U, MacDonald NJ, Benedict M and Leone A: Nm23 and breast cancer metastasis. Breast Cancer Res Treat 25: 175-187, 1993.

28. MacDonald NJ, de la Rosa A and Steeg PS: The potential roles of $n m 23$ in cancer metastasis and cellular differentiation. Eur J Cancer 31A: 1096-1100, 1995.

29. Salerno M, Palmieri D, Bouadis A, Halverson D and Steeg PS: Nm23-H1 metastasis suppressor expression level influences the binding properties, stability, and function of the kinase suppressor of Ras1 (KSR1) Erk scaffold in breast carcinoma cells. Mol Cell Biol 25: 1379-1388, 2005.

30. Chen $\mathrm{X}, \mathrm{Xu} \mathrm{Z}$ and Wang Y: Recent advances in breast cancer metastasis suppressor 1. Int J Biol Markers 26: 1-8, 2011.

31. Kodura MA and Souchelnytskyi S: Breast carcinoma metastasis suppressor gene 1 (BRMS1): Update on its role as the suppressor of cancer metastases. Cancer Metastasis Rev 34: 611-618, 2015. 